\title{
Natural strategies for the control of Paenibacillus larvae, the causative agent of American foulbrood in honey bees: a review
}

\author{
Rosa Maria Alonso-Salces ${ }^{1,3}$, Noelia Melina Cugnata ${ }^{1,3}$, Elisa Guaspari ${ }^{1,3}$, \\ Maria Celeste Pellegrini ${ }^{1,2}$, Inés Aubone ${ }^{1}$, Fiorella Giselle De Piano ${ }^{3,4}$, \\ Karina Antunez ${ }^{5}$, Sandra Rosa Fuselli ${ }^{1,2}$

\footnotetext{
${ }^{1}$ Grupo de Investigación Microbiología Aplicada, Centro de Investigación en Abejas Sociales, Facultad de Ciencias Exactas y Naturales, Universidad Nacional de Mar del Plata, Dean Funes, B7602AYL, 3350, Mar del Plata, Argentina ${ }^{2}$ Comisión de Investigaciones Científicas, La Plata, Argentina

${ }^{3}$ Consejo Nacional de Investigaciones Científicas y Técnicas, Buenos Aires, Argentina Mar del Plata, Mar del Plata, Argentina

${ }^{5}$ Departamento de Microbiología, Instituto de Investigaciones Biológicas Clemente Estable, Montevideo, Uruguay
} \\ ${ }^{4}$ Cátedra de Apicultura, Departamento de Producción Animal, Facultad de Ciencias Agrarias, Universidad Nacional de
}

Received 16 May 2016 - Revised 8 October 2016 - Accepted 16 November 2016

\begin{abstract}
American foulbrood (AFB) is a severe bacterial disease that affects larvae of honey bees (Apis mellifera). The causative agent of AFB is the spore-forming bacteria Paenibacillus larvae. The use of antibiotics for the control of AFB has led to the appearance of resistant bacterial strains and residues in beehive products. Nowadays, antibiotics are legally banned in several countries, and the affected colonies have to be destroyed by burning the hives. Therefore, the development of alternative methods for the control and prevention of AFB is necessary. In this context, different natural strategies based on the application of essential oils, plant extracts, propolis, royal jelly, nonconventional natural molecules, bacteria, and bacteriocines, have been studied in vitro and in vivo for the prevention and control of $P$. larvae. The experimental data achieved from these studies are reviewed and discussed in the present review, which intend to be a starting point for future research in the field.
\end{abstract}

\section{Paenibacillus larvae / American foulbrood / Apis mellifera / natural products}

\section{INTRODUCTION}

American foulbrood (AFB) is the most severe bacterial disease that affects honey bees, having a nearly cosmopolitan distribution (Genersch

Electronic supplementary material The online version of this article (doi:10.1007/s13592-016-0483-1) contains supplementary material, which is available to authorized users.

Corresponding author: S. Fuselli, sfuselli@gmail.com

Manuscript editor: David Tarpy
2010). AFB only kills infected honey bee larvae; however, it eventually leads to the collapse of the entire colony when left untreated. AFB is considered to be very contagious; therefore, it is a notifiable disease in most countries (Djukic et al. 2014). AFB's causative agent is Paenibacillus larvae, which is a flagellated gram-positive bacterium, whose main characteristic is the formation of highly resistant endospores. This pathogen affects the breeding during the larval or pupal stages (Genersch et al. 2006); its spores being the infectious form. Honey bee larvae are more susceptible to infection during the first $36 \mathrm{~h}$ after egg hatching (Ashiralieva and Genersch 2006), indeed only ten 
spores are required to make a larva of less than $24 \mathrm{~h}$ old ill (Bamrick 1967). However, at later larval developmental stages, spore doses needed to successfully infect a larva are too high to occur under natural conditions (Genersch et al. 2005). The infection takes place by the ingestion of the spores with the food provided by adult worker bees (nurses) to the larvae (Hansen and Brodsgaard 1999). Spores germinate in the larval midgut and massively proliferate for several days. At a later stage, $P$. larvae reaches the peritrophic matrix, penetrates into the epidermal cells, producing septicemia, and finally causing the death of the larva. In the last instance, the corpses are digested by vegetative bacterial cells and converted to dried scales containing millions of $P$. larvae spores (Hansen and Brodsgaard 1999; Cornman et al. 2013; Djukic et al. 2014). The most conspicuous symptoms in colonies suffering from clinical AFB disease are irregular brood capping, showing capped and uncapped cells scattered irregularly across the brood frames; dark, sunken, and often punctured caps emitting a "foul" odor; brown glue residues of the dead larvae forming a characteristic ropey thread when it is pulled out with a wooden stick or a match; and a hard scale of larval residues at the bottom of the cell. Traditional AFB diagnosis is based on the observation of these clinical symptoms in the beehive and on the microbial cultivation of material from infected colonies (De Graaf et al. 2006).

The resistance of $P$. larvae endospores is a main issue in the control and prevention of AFB because these endospores can survive for more than 35 years in honey and/or on the beekeeping material and resist high temperatures as well as the action of the most commonly used disinfectants (Bamrick 1967). Most treatments are based on the use of broad spectrum antibiotics, which, in most cases, have been used continuously and excessively. Indeed, different antibiotics, such as sulfathiazole and oxytetracycline hydrochloride (OTC), are able to inhibit the growth of $P$. larvae, but its use and abuse for decades led to the appearance of resistant strains and residues that contaminate beehive products. For these reasons, the use of antibiotics for AFB treatment and prevention is forbidden in several countries, and the affected colonies have to be destroyed by burning the hives (Mutinelli 2003). This action represents a drastic solution with a high cost for beekeepers, and furthermore, it cannot be used as a preventive method to combat AFB (Kochansky et al. 2001). In this context, the development of alternative and effective methods for the control and prevention of AFB disease is crucial. These methods should consider the evidence of bacterial-resistant phenomenon and comply with strict EU policies as well as with current trends of green consumerism (Lewis and Ausubel 2006). In the present review, the research studies focused on the development of natural strategies for the control and prevention of AFB carried out so far are summarized, including the use of essential oils, plant extracts, propolis, royal jelly, nonconventional natural molecules, bacteria, and bacteriocines for the aimed purpose.

\section{NATURAL PRODUCTS FOR THE PREVENTION AND CONTROL OF AMERICAN FOULBROOD}

\subsection{Essential oils}

Essential oils (EOs) are natural volatile and complex products obtained as secondary metabolites of aromatic plants, having different biological effects (anticancer, anti-inflammatory, insect repellent, antimicrobial, antiviral, and antioxidant). Since EOs affect many targets at the same time, no cases of resistance or adaptation have been detected (Adorjan and Buchbauer 2010). Several EOs have been evaluated for the in vitro and in vivo control of $P$. larvae, as well as their acute oral toxicity to Apis mellifera (Tables I, II, and III in the Electronic supplementary material).

\subsubsection{In vitro assays to control P. larvae}

EOs from Achyrocline satureioides, Carum carvi, Cinamomum sp., Cinnamomum zeylanicum, Citrus paradise, Cuminum cyminum, Cymbopogon citratus, Eucalyptus cinerea, Melaleuca alternifolia, Mentha 
piperita, Minthostachys verticillata, Origanum majorana, Origanum vulgare, Polygonum bistorta, Salvia officinalis and Salvia sclarea, Syzygium aromaticum, Tagetes minuta, Thymus vulgaris, Verbena, Pimenta dioica (L.) Merr., Litsea cubeba Pers., Trachyspermum ammi L., Mentha arvensis L., Mentha spicata L., Illicium verum Hook.f, Myristica fragrans Gronov., Cinnamomum camphora (L.) J. Presl., Ocimum tenuiflorum L., Daucus carota L., Zingiber officinale Rosc., and Pelargonium graveolens L., were able to inhibit the growth of $P$. larvae, as evinced by the agar diffusion technique (Floris et al. 1996; González and Marioli 2010; Roussenova 2011; Cecotti et al. 2012; Kuzyšinová et al. 2014; Ansari et al. 2015). EOs from Cimbopogon citratus, Cinnamomum aromaticum, Citrus reticulate var madurensis, Citrus paradisi, Heterothalamus alienus, M. alternifolia, M. piperita, O. majorana, O. vulgare, S. sclarea, S. aromaticum, T. minuta T. vulgaris, as well as the mixtures of C. citratus and T. vulgaris EOs $(20: 80, v / v)$, and C. citratus, T. vulgaris, Satureja hortensis, O. vulgare, and Ocimum basilicum EOs (5:11:21:26:37, $v / v / v / v / v)$ also showed antibacterial activity against $P$. larvae by the agar dilution technique (Alippi 1996; Alippi et al. 2001; Roussenova 2011). EOs from Citrus sinensis, Cinamomum spp., C. cyminum, Eugenia spp., T. vulgaris, Verberna spp., Acantholippia seriphioides, C. zeylanicum, H. alienus Spreng., Pimpinella anisum, Foeniculum vulgare, and Eucalyptus globulosus, and the mixture of T. vulgaris EO, thymol and Cinamomum zeylanicum EO (62.5:25:12.5, v/v/v) exhibited antibacterial activity against $P$. larvae by the broth macrodilution technique (Floris et al. 1996; Fuselli et al. 2005, 2006a, b; Ruffinengo et al. 2006; Gende et al. 2008a, b, 2009b, 2010b). Cinamomum spp. EO also showed high sporicidal activity (Floris et al. 1996). The mixture of T. vulgaris EO, thymol, and Cinnamomum zeylanicum EO (62.5:25:12.5, v/v/v) presented lower minimum inhibitory concentration (MIC) and minimum bactericidal concentration (MBC) than the pure EOs (Fuselli et al. 2006a). Gende et al. (2010b) attributed E. globulosus EO antimicrobial activity to limonene, one of its constituents
(Gende et al. 2010b). EOs from Artemisia absinthium, Artemisia annua, Lepechinia floribunda, C. paradisi, Cymbopogon nardus, Melaleuca viridiflora, C. zeylanicum, Rosmarinus officinalis, Carapa guianensis, Copaifera officinalis, M. alternifolia, Mentha aff. arvensis, Mentha aff. rotundifolia, P. dioica (L.) Merr., L. cubeba Pers., T. ammi L., M. arvensis L., M. spicata L., I. verum Hook.f, M. fragrans Gronov., C. camphora (L.) J. Presl., O. tenuiflorum L., D. carota L., Z. officinale Rosc., and $P$. graveolens L. showed antibacterial activity against $P$. larvae by the broth microdilution technique (Fuselli et al. 2007, 2008a, b, 2009, 2010; Gende et al. 2010a, 2014; Maggi et al. 2011; Santos et al. 2012, 2014; Ansari et al. 2015; de Almeida Vaucher et al. 2015). The antimicrobial activities against P. larvae of the EOs of $M$. aff. arvensis and $M$. aff. rotundifolia from Argentina were assigned to some of their constituents, such as menthol, menthone, menthofuran, and piperitone oxide (Gende et al. 2014).

\subsubsection{Toxicity assays on A. mellifera}

C. sinensis, Cinamomum spp., C. zeylanicum, C. cyminum, Eugenia spp., T. vulgaris, and Verbena EOs were nontoxic for adult honey bees when they were fed with candy and the EO at different concentrations by systemic administration (Floris et al. 1996; Gende et al. 2009b). C. citratus, T. vulgaris and O. basilicum EOs, as well as $C$. citratus and T. vulgaris EO mixture $(50: 50, v / v)$ were moderately toxic to adult honey bees. However, the C. citratus, T. vulgaris, and Coriandrum sativum EO mixture (33.3:33.3:33.3, $v / v / v)$ presented negative mortality curves, meaning that there was less mortality at high doses. This fact disclosed that bees did not consume candy with high quantities of $C$. sativum EO (Albo et al. 2008). When a solution containing a certain amount of EO was sprayed over a group of honey bees, T. minuta, C. guianensis, and C. officinalis EOs resulted to be nontoxic for adult bees (Eguaras et al. 2005; Santos et al. 2012); whereas $M$. alternifolia EO caused the death of the bees after 7 days of treatment. Nevertheless, the use of nanoparticles of 
M. alternifolia EO did not produce any toxic effect on honey bees (Santos et al. 2014). Eucalyptus globosus and $R$. officinalis EOs and the nanoemulsion of Carapa officinalis EO were not toxic for adult worker honey bees when they were completely exposed to the EO, i.e., bees were in contact with the EO and ingested the EO (Gende et al. 2010a; Maggi et al. 2011; de Almeida Vaucher et al. 2015). The nanoemulsion of C. guianensis EO exhibited a toxic effect for larvae and adult honey bees, whereas the nanoemulsion of $C$. officinalis $\mathrm{EO}$, a low toxic effect on larvae (de Almeida Vaucher et al. 2015).

\subsubsection{In vivo assays to control American foulbrood}

The treatment of artificially infected nuclei of honey bee colonies with $C$. zeylanicum EO by systemic administration prevented and controlled AFB (Floris et al. 1996; Gende et al. 2009a). T. vulgaris, C. citratus, O. vulgare, and $S$. hortensis EOs were tested individually and as mixtures on artificially infected nuclei, even though AFB was neither controlled nor prevented by these treatments (Albo et al. 2001, 2003).

\subsection{Plant extracts}

Several plant extracts have been evaluated for the in vitro control of $P$. larvae and their acute oral toxicity to honey bees (Tables IV and V in the Electronic supplementary material).

\subsubsection{In vitro assays to control P. larvae}

The antimicrobial activity of different extracts of Flourensia riparia, Flourensia fiebrigii, and Flourensia tortuosa against $P$. larvae were studied by the agar diffusion technique. The chloroform, ethyl ether, and hexane extracts at different concentrations (100 to $50000 \mu \mathrm{g} \mathrm{mL}{ }^{-1}$ ) showed inhibitory effect by this technique (Reyes et al. 2013). Dichloromethane and methanol extracts from the inflorescences of various species of Hypericum genus (100 $\mu \mathrm{g}$ of dry extracts) also presented antibacterial activity against $P$. larvae. When applying as little as $25 \mu \mathrm{g}$ of these extracts, the inhibition halo diameters were comparable with those achieved when applying $1000 \mu \mathrm{g}$ of lactic acid (positive control) (Hernández-López et al. 2014). The antimicrobial activities of Azadirachta indica (Neem) and Vitex trifolia (Barbaka) crude aqueous extracts $(20,40$, and $60 \mathrm{mg} \mathrm{mL}^{-1}$ disk $^{-1}$ ) against $P$. larvae resulted to be dose dependent, with the larger inhibition zones corresponding to Barbaka plant (Anjum et al. 2015). F. riparia ethyl ether and chloroform extracts as well as the $F$. fiebrigii ethyl ether extract inhibited $P$. larvae by the agar dilution technique (Reyes et al. 2013). Water extracts of A. satureioides, Chenopodium ambrosioide, E. cinerea, Gnaphalium gaudichaudianum, Lippia turbinata, Marrubium vulgare, $M$. verticillata, and $T$. minuta also inhibited the growth of $P$. larvae by this technique (González and Marioli 2010). The MIC values of the hexane extract of $A$. satureioides obtained by the broth microdilution and the agar dilution techniques varied from 16 to $125 \mu \mathrm{g} \mathrm{mL}^{-1}$ (Sabaté et al. 2012). In another study, the hexane, benzene, ethy ether, and ethyl acetate extracts of $A$. satureioides yielded MIC values of $60,131,773$, and $6545 \mu \mathrm{g} \mathrm{mL}^{-1}$, respectively, by the broth microdilution method (González et al. 2015). The MIC of the Melia azedarach ethanolic extract determined by the broth macrodilution technique was $5000 \mu \mathrm{g} \mathrm{mL}^{-1}$ (Gende et al. 2008b). The dichloromethane, ethyl acetate, $n$-butanol fractions, and the crude extract obtained with ethanol-water $(7: 3, v / v)$ of Scutia buxifolia (Boligon et al. 2013); the methanoldichloromethane $(1: 1, v / v)$ extracts of Humulus lupulus and Myrtus communi (Flesar et al. 2010); the Calendula officinalis and Nasturtium officinale crude extracts obtained with ethanolwater $(7: 3, v / v)$; the ethanol-water $(8: 2, v / v)$ extract of Laurus nobilis (Damiani et al. 2014); and the Cariniana domestica $n$-butanol and ethyl acetate fractions (Piana et al. 2015) caused the inhibition of $P$. larvae growth by the agar dilution method.

\subsubsection{Toxicity assays on A. mellifera}

H. lupulus and M. communis methanoldichloromethane extracts, evaporated to dryness and solubilized in DMSO 5\% $(v / v)$, were not 
toxic at concentrations as high as $100 \mu \mathrm{g}$ bee ${ }^{-1}$ by systemic administration (Flesar et al. 2010). $S$. buxifolia crude extract obtained with ethanolwater $(7: 3, v / v)$ and their $n$-butanol, ethyl acetate, and dichloromethane fractions, re-dissolved in DMSO to reach final concentrations of 50, 25, 6.25 , and $1.56 \mathrm{mg} \mathrm{mL}^{-1}$, respectively, were tested by spraying honey bees. No toxic effects for the bees were detected after 15 days of observation (Boligon et al. 2013). Similarly, no toxicity was observed for $N$. officinale crude extract and C. domestica $n$-butanol fraction re-dissolved in DMSO during the 15 days of treatment (Piana et al. 2015). However, some deaths of honey bees occurred during the first 3 days of treatment with C. officinalis and C. domestica ethyl acetate fractions. Complete exposure was implemented to analyze the effect of the chloroform and ethyl ether extracts from $F$. riparia and the ethyl ether extracts from $F$. fiebrigii on adult honey bees. These extracts, re-dissolved in ethanol at $96 \%$ $(v / v)$, did not show lethal effects on exposed bees during in vitro conditions even at the highest concentration assayed (125 mg mL $\mathrm{mL}^{-1}$ ) (Reyes et al. 2013).

\subsection{Propolis}

Propolis is a natural product derived from plant resins, produced by honey bees to seal the walls and entrance of the hive, and contributes to protect the colony against different pathogens. It is made of a complex mixture of different chemical compounds (from 80 to 300 ); the main components having been identified as polyphenols (flavonoids and phenolic acids), terpenoids, steroids, and aminoacids, whose concentrations vary according to the geographical and botanical origin of the propolis (Burdock 1998). Several biological properties such as antioxidant (da Silva et al. 2006), antimicrobial (Boonsai et al. 2014), antifungal (Kujumgiev et al. 1999), antiviral (Manolova et al. 1985), hepatoprotective, immunomodulatory, and anti-inflammatory (Burdock 1998) have been ascribed to propolis. In this sense, several papers account for the use of propolis from different geographical origins as antimicrobials against P. larvae to control AFB on A. mellifera
(Table VI, VII, and VIII in the Electronic supplementary material).

\subsubsection{In vitro assays to control P. larvae}

Mlagan and Sulimanovic (1982) tested propolis from Yugoslavia and found that 5\% $(v / v)$ and $10 \%(v / v)$ propolis extracts inhibited the growth of $P$. larvae by the agar diffusion technique. Ethanolic extracts of propolis from Uruguayan apiaries also showed inhibition by this technique (Antúnez et al. 2008). Brazilian propolis from Baccharis dracunculifolia and Vernonia polyanthes, and North American propolis from Populus spp. presented activity as well. These propolis had similar effects to vancomycin, but a much lower amount of antibiotic $(30 \mu \mathrm{g})$ than of propolis (9 $\mathrm{mg}$ on average) was required (Bastos et al. 2008). The ethanolic extracts of propolis from Romania (at $10 \mathrm{mg} \mathrm{mL}^{-1}$ ) also inhibited the growth of $P$. larvae by this technique; this activity was attributed to flavones, flavonols, flavanones, and dihydroflavonols (Mihai et al. 2012). Bíliková et al. (2013) studied Bulgarian poplar propolis and their crude ethanolic extract as well as their petrol ether fraction and ethyl acetate fraction by the agar diffusion and the broth microdilution techniques. In this case, $100 \mu \mathrm{g}$ of propolis extract was necessary to cause the same effect as $10 \mathrm{mg}$ of OTC. Moreover, five individual components and a mixture of caffeates isolated from that propolis also showed antimicrobial activity, with pinocembrin and pinobanksin-3-O acetate being the components with the highest antimicrobial effect (Bíliková et al. 2013). Boonsai et al. (2014) studied the methanol, dichloromethane, and hexane extracts of propolis from Thailand by the same techniques; only the methanolic extracts (100 mg mL $\mathrm{mL}^{-1}$ ) exhibited antimicrobial activity, which was attributed to cardanol (a phenolic compound of the Anacardiaceae family). Lindenfelser (1968) examined the activity against $P$. larvae of 15 propolis samples from the USA and determined their MICs by the broth macrodilution technique. All samples showed similar levels of bactericidal activity at concentrations smaller than $10 \mu \mathrm{g} \mathrm{mL}^{-1}$. As well, MICs of Uruguayan propolis were estimated by this technique, ranging between $0.32 \%$ 
$(v / v)$ and $0.64 \%(v / v)$ (Antúnez et al. 2008). Most ethanolic extracts of propolis samples collected in apiaries from different USA regions were found to inhibit $P$. larvae growth in a dosedependent manner by the broth microdilution technique (Wilson et al. 2015).

\subsubsection{Toxicity assays on A. mellifera}

The acute oral toxicity of several propolis on adult honey bees has been studied by the systemic administration technique (Table VII in the Electronic supplementary material). The ethanolic extract of propolis from Uruguay was not toxic for adult honey bees at least at 50\% ( w/v) (Antúnez et al. 2008). In contrast, the ethanolic extract of propolis from Egyptian old wax comb $\left(\mathrm{LC}_{50}=1.404\right)$ were found to be more toxic than Egyptian $\left(\mathrm{LC}_{50}=8.223\right)$ and Chinese propolis extracts $\left(\mathrm{LC}_{50}=15.047\right)$ (Kamel et al. 2013).

\subsubsection{In vivo assays to control American foulbrood}

Field studies have been conducted using the systemic administration and the spraying procedure (Table VIII in the Electronic supplementary material). Lindenfelser (1968) showed that, despite their proven in vitro antimicrobial activities against $P$. larvae, North American propolis were not effective on naturally infected colonies. When bees were fed with propolis diluted in honey at a concentration of $500 \mu \mathrm{g} \mathrm{mL}^{-1}$ (systemic administration), new infection was not detected while the treatment was still in progress; however, when treatment was discontinued, the disease reappeared. No toxic effects were noted on the adult bees of this colony, even though many deformed young bees emerged (Lindenfelser 1968). The efficiency of Egyptian, Chinese, and old wax comb Egyptian propolis extracts to control AFB on artificially infected bee colonies was evaluated using hybrid carniolan race colonies. The addition of $0.05 \%(w / v)$ of Egyptian propolis to the feed had a highly significant positive influence on controlling the growth of P. larvae, resulting in 100\% bacterial reduction, as it happened when tylosin was used (200 mg). The activity of Chinese and old wax comb Egyptian propolis extracts at 0.1,
0.05 , and $0.025 \%(w / v)$ were significantly different when compared with untreated colonies (Kamel et al. 2013). In another case, colonies from an apiary in Uruguay that had presented AFB on previous years (but with no clinical symptoms) were treated by aspersion and by feeding with propolis ethanolic extracts $(6 \%, v / v)$. After 21 and 42 days of the application of the treatments, the number of $P$. larvae spores per gram of honey was significantly lower in the colonies treated with propolis ethanolic extracts than in the untreated colonies (Antúnez et al. 2008).

\subsection{Royal jelly}

Royal jelly (RJ) or larval jelly (LJ) is the larval diet of queen larvae and worker larvae secreted by the hypopharyngeal and mandibular glands of worker honey bees. The main components of jellies are carbohydrates, peptides, proteins, fat, and low molecular weight compounds (Bogdanov 2011). Low molecular weight proteins and peptides of RJ seem to play a host-defense role against honey bee pathogens (Bíliková et al. 2001). The first antibiotic compound identified in RJ was the fatty acid 10 -hydroxi- $\Delta 2$-decenoic acid. Afterwards, a potent antibacterial protein, named royalisin (currently called defensin 1 ), found in RJ was also described. Royalisin has specific activity against various gram-positive bacteria at low concentrations but not against gram-negative bacteria (Fujiwara et al. 1990). Antibacterial (Nascimento et al. 2015), immunoregulation (Sugiyama et al. 2012), antitumoral (Kimura 2008), anti-inflamatory (Kohno et al. 2004), reproprotective action (Jalali et al. 2015), antiviral (Hashemipour et al. 2014), and antioxidant (Pavel et al. 2014) activities have been attributed to RJ. In particular, the in vitro antimicrobial activity of RJ from different geographical origins against $P$. larvae has been also reported in literature (Table IX in the Electronic supplementary material). The use of RJ to control P. larvae growth was first observed by Hornitzky et al. (1998). Later, it was reported that purified royalisin also had inhibitory effect against the pathogen by the agar diffusion technique, even at the lowest tested concentration $\left(5.4 \mu \mathrm{g} \mathrm{mL}^{-1}\right)$ (Bíliková et al. 2001). Other proteins found in RJ 
were identified as apalbumins. The most abundant ones, apalbumin-2 and apalbumin-2a, were purified, and their activity against $P$. larvae was evaluated in liquid cultures. Apalbumin-2a $18.6 \mu \mathrm{M}$ inhibited its growth at a similar rate than OTC, while apalbumin-2 did not present antibacterial activity at all (Bíliková et al. 2009). The analyses of RJs collected from individual colonies at two apiaries, one of which having shown incidence of $\mathrm{AFB}$, revealed differences in the content of the antibacterial peptide. Most colonies from the apiary with AFB produced RJs with higher amounts of royalisin than the colonies from the healthy apiary. These results suggested that the differences in the peptide contents are related to genetic variability among colonies. However, it is also possible that the presence of $P$. larvae could have affected the content of royalisin in the RJs (Bachanová et al. 2002).

\subsection{Nonconventional natural molecules}

This heterogeneous group includes a number of compounds which share one common characteristic: they are pure natural substances, either commercial, such as fatty acids or that have been obtained from natural sources, such as fungal strains or plants. Shimanuki et al. (1992) reported the inhibition of AFB by an ethanolic extract of chalkbrood mummies (A. mellifera larvae infected by Ascosphaera apis fungus). This fact led scientists to seek the identity of the active compound. Several studies on the evaluation of nonconventional natural molecules used for the in vitro control of $P$. larvae and their toxicity on honey bees have been published (Tables X and XI in the Electronic supplementary material).

\subsubsection{In vitro assays to control P. larvae}

Lokvam and Braddock (1999) performed agar diffusion bioassays to determine the antimicrobial activity of resin from both sexes of Clusia grandiflora, a native species from South America. These resins showed pronounced inhibitory activity against $P$. larvae. The female plant resin inhibition zones were higher than those produced by the male plant resin. Chamone I (benzophenone isolated from the trunk latex of C. grandiflora Splitg.
(Clusiaceae)) and nemorosone II (benzophenone isolated from the pollinator reward resin of the female flowers of the same plant) demonstrated to have a strong inhibitory effect on $P$. larvae (Lokvam et al. 2000). Linoleic acid (isolated from mycelia and spores of A. apis) was shown to be active against $P$. larvae at concentrations down to $2.5 \mu \mathrm{g} \mathrm{disk}^{-1}$ (Feldlaufer et al. 1993a). Lauric and tridecanoic acids were found to be the most active saturated fatty acids against $P$. larvae, while palmitoleic and linoleic acids were the most active among the unsaturated ones. The introduction of a double bond or multiple double bonds seems to be necessary to maintain the antibiotic activity once the chain length of the fatty acid exceeds 14 carbons (Feldlaufer et al. 1993b). Fifteen fatty acids were proved to have antibacterial activity against P. larvae. The majority of the tested acids exhibited activity at the highest quantity tested $(250 \mu \mathrm{g})$, except for myristoleic and lauric acids, which also showed reduced activity with diffusion disks containing $25 \mu \mathrm{g}$ of the molecule (Hornitzky 2003). Ltenuazonic acid (isolated from Alternaria raphani and Alternaria brassicicola cultures) was proved to be a specific antibiotic against $P$. larvae (MIC of 1$5 \mu \mathrm{g}$ disk $^{-1}$ ) by the agar diffusion technique, even though the MIC of OTC and gentamicine were lower $\left(0.5 \mu \mathrm{g} \mathrm{disk}^{-1}\right)$ (Gallardo et al. 2004). By the agar dilution technique, L-tenuazonic acid yielded a MIC value of $32 \mu \mathrm{g} \mathrm{mL}{ }^{-1}$, similar to OTC (Gallardo et al. 2004). Exiguaflavanone K and 8-prenyldihydroisorhamnetin isolated from $F$. riparia showed antimicrobial activity against P. larvae, as well as 8-prenyleryodictiol and (2S)8 - ( $3^{\prime \prime}$ - methylbut - $2^{\prime \prime}$ - e ny 1$)-7,3^{\prime}, 4^{\prime}$ trihydroxyflavanone isolated from F. fibrigii (Reyes et al. 2013). The antimicrobial activity of six pure compounds isolated from species of the Hypericum genus: Hypericum canariense, Hypericum drummondii, Hypericum mutilum, and Hypericum perforatum on $P$. larvae vegetative cells were evaluated by the broth macrodilution technique (Hernández-López et al. 2014). Uliginosin B isolated from $H$. mutilum, 7-epiclusianone from $H$. canariense, and hyperforin from the medicinal species $H$. perforatum presented antimicrobial activity against $P$. larvae. Hyperforin was also tested on $P$. larvae spores. When using $10 \mu \mathrm{g}$ of such compound, the CFU count of P. larvae 
(4.40 CFU $\mathrm{mL}^{-1}$ ) was lower than the negative control (114.6 CFU mL ${ }^{-1}$ ) (Hernández-López et al. 2014). The antimicrobial activity against $P$. larvae of glycerol monolaurate and glycerol monolaurate nanocapsules were found to be significantly different, with MIC values being 62.2 and $142.8 \mu \mathrm{g} \mathrm{mL}^{-1}$, respectively (Lopes et al. 2016). Commercial compounds of plant origin, such as sanguinarine, thymoquinone, capsaicin, nordihydroguaiaretic acid, and trans-2-hexenal, showed antimicrobial activity against $P$. larvae by the broth microdilution technique (Flesar et al. 2010).

\subsubsection{Toxicity assays on A. mellifera}

The acute oral toxicity of capsaicin, nordihydroguaiaretic acid, sanguinarine, thymoquinone, and trans-2-hexenal was assessed on A. mellifera subsp. carnica by systemic administration. $\mathrm{LD}_{50}$ values for capsaicin and thymoquinone were higher than $100 \mu \mathrm{g} \mathrm{bee}^{-1}$, and for nordihydroguaiaretic acid and trans-2hexenal, higher than $200 \mu \mathrm{g}$ bee $^{-1}$. Therefore, these compounds were considered to be "virtually nontoxic." $\mathrm{LD}_{50}$ value for sanguinarine was $153 \mu \mathrm{g}$ bee $^{-1}$, which is above the potential therapeutic dose; hence, it poses no danger to honey bees (Flesar et al. 2010). Glycerol monolaurate resulted to be highly toxic on adult worker bees when tested at one- and twofold of the MIC. In contrast, glycerol monolaurate nanocapsules were proved to be virtually nontoxic when using the spraying procedure (Lopes et al. 2016).

\subsection{Bacteria and bacteriocins}

Probiotics are living microorganisms which, when administered in adequate amounts, confer a health benefit on the host. These microorganisms should fulfill a group of requirements, among others: ability to adhere to cells; exclude or reduce pathogenic adherence; persist and multiply; and produce acids, hydrogen peroxide, and bacteriocins antagonistic to pathogen growth. Moreover, it is important that the microorganisms are safe, and therefore, noninvasive, noncarcinogenic, and nonpathogenic. A recommended alternative is to isolate microorganisms from the same host were they are applied (FAO/WHO 2006). Honey bees support a diverse microbial biome (Engel et al. 2012; Moran et al. 2012; Powell et al. 2014), which can be an important source for probiotics. Lactic acid bacteria $(\mathrm{LAB})$ are usually found within bee guts and are known to protect their hosts via antimicrobial metabolites such as organic acids, hydrogen peroxide, and antimicrobial peptides, as well as modulation of host immune response (Vásquez et al. 2012). Many of these beneficial bacteria have been isolated from honey bee adults and larvae, and beehive products such as honey and pollen (Evans and Armstrong 2005, 2006; Yoshiyama et al. 2013; Jaouani et al. 2014). Bacteriocins are bacterial ribosomally synthesized, extracellular peptides, or proteins with an antibacterial activity usually against bacteria closely related to the producer (De Vuyst and Vandamme 1994; Riley and Wertz 2002). Bacteria and bacteriocins have also been studied for the control of P. larvae (Table XII in the Electronic supplementary material).

\subsubsection{In vitro assays to control P. larvae}

Bacteria isolates, obtained from honey bee larvae or the gut of adult $A$. mellifera, belonging to the genera Brevibacillus, Stenotrophomonas, $\mathrm{Ba}$ cillus, Acinetobacter, Lactobacillus, and Bifidobacterium showed antimicrobial activity against $P$. larvae by the agar diffusion technique (Evans and Armstrong 2006) (Forsgren et al. 2010). Many of these isolates were proved to produce surfactin, an antibiotic with antitumoral and antiviral action (Sabaté et al. 2009). Microorganisms (Escherichia coli, Providencia alcalifaciens, Splingomonas melonis, Bacillus subtilis and $\mathrm{Ba}$ cillus cereus, Enterococcus, Lactobacillus, and Weissella ) isolated from the midgut of Apis cerana japonica also exhibited inhibitory effects on P. larvae (Yoshiyama and Kimura 2009; Yoshiyama et al. 2013). Isolates of different species of aerobic spore-forming bacteria (ASFB) isolated from honey samples and brood combs presented antagonism with $P$. larvae. Ten of these ASFB strains were identified as B. subtilis, Bacillus umilus, Bacillus licheniformis, Bacillus megaterium, B. cereus, and Brevibacillus laterosporus (Alippi and Reynaldi 2006). Besides the activity of bacterial cells, cell-free supernatant of Lactobacillus acidophilus, Lactobacillus 
crispatas, and Lactobacillus jonsonii obtained from the gut of worker honey bees also showed antimicrobial activity against $P$. larvae (Audisio et al. 2011). The antibacterial activity against P. larvae of both, the cell-free supernatant of $\mathrm{Ba}$ cillus thuringiensis subsp. entomocidus and of entomocin 110 (bacteriocin isolated from the same species of Bacillus), was evaluated by the agar diffusion technique, showing inhibition of all 17 strains of $P$. larvae tested (Cherif et al. 2008). Regarding the cell-free supernatants extracts of 36 Enterococcus isolates, 20 of them showed strong inhibition, and the remaining 16 isolates caused a mild inhibition of $P$. larvae (Jaouani et al. 2014). Soil bacteria are also sources of microorganisms with antibacterial activity against P. larvae. Nguyen and Kim (2015a, b) proved the existence of a strong antimicrobial activity of Bacillus polymachus $\mathrm{T}^{2} 15^{\mathrm{T}}$ and Streptomyces polymachus $\mathrm{T} 258^{\mathrm{T}}$ on P. larvae. As well, an antimicrobial substance produced by Bacillus amyloliquefaciens (soil bacteria) also presented activity on vegetative cells and spores of P. larvae (Benitez et al. 2012).

\subsubsection{Toxicity assays on A. mellifera and exposure bioassays}

Bacteria and bacteriocins toxicity on A. mellifera has been determined by the systemic administration method. Larval food was supplemented with crude and purified fractions of $B$. amyloliquefaciens antimicrobial factor (800 AU mL ${ }^{-1}$ ). Honey bee larvae showed a mortality of $25.5 \%$, while the mortality in the control group was $15 \%$ (Benitez et al. 2012). In the exposure bioassays, honey bee larvae were fed with a mixture of Lactobacillus kunkeii, Lactobacillus sp., Bifidobacterium asteroids, and Bifidobacterium coryneforme. The overall effect of adding the LAB mixture to the larval feed was a significant reduction in the number of infected larvae, irrespectively of the infective dose (Forsgren et al. 2010).

\section{DISCUSSION}

Taking into account the negative effects of P. larvae on honey bee colonies and the drawbacks of traditional methods to deal with AFB disease, the development of alternative and effective methods for its control and prevention has become mandatory. Among the natural strategies that have been developed during the last years, the use of EOs is a promising therapy. Cinamomum zeylanicum EO presented the best characteristics as natural product to control AFB, showing the highest antimicrobial activity, and being effective on AFB control on beehives and nontoxic for adult honey bees, even though toxicity on honey bee larvae has still to be tested. The nanoemulsion of $C$. officinalis EO also showed high antimicrobial activity against $P$. larvae and presented a low toxic effect on larvae; hence, it has been suggested as an alternative method to fight AFB. Besides, nanoemulsions can potentiate the antibacterial effect of EOs and protect against volatility. Enhancement of the treatment effectiveness may also be possible if EOs are used together with other active ingredients, such as individual natural compounds, plant extracts, other EOs or their main constituents. As well, propolis and RJ and its proteins, royalisin and apalbumin-2a, presented in vitro inhibitory effect against $P$. larvae; thus, future research should focus on the role of these substances in protecting honey bee larvae against $P$. larvae infection. Moreover, a large number of diverse nonconventional natural molecules have been reported to present significant growth-inhibitory action on P. larvae and low toxicity to bees. Among them, lauric acid and tridecanoic acid are potentially useful in suppressing AFB, being already commercially available for different purposes. Probiotics can also improve honey bee health, indeed several bacterial isolates obtained from honey bees or beehive products were able to inhibit in vitro the growth of $P$. larvae, and the oral administration of a mixture of lactic acid bacteria to the larval feed led to a significant reduction in the number of infected larvae.

Despite all this progress in alternative natural strategies to fight AFB disease, the fact that P. larvae is a spore-forming bacterium is the main limitation to any of the treatments proposed to the present against this bacterium due to the wellknown resistance of their endospores. Some of the natural products studied for their antimicrobial activity against $P$. larvae have also shown sporicidal activity, such as Cinamomum spp. EO, some propolis ethanolic extracts, hyperforin and a 
substance produced by B. amyloliquefaciens; however, none of them have achieved the eradication of AFB in honey bee colonies yet.

\section{CONCLUSIONS}

The research performed presently to study the in vitro and in vivo antimicrobial activity of natural products against $P$. larvae, as well as the toxicity of these natural products on adult honey bees, has been thoroughly reviewed throughout this paper. Regarding that honey bee larvae are the target of AFB disease, future research should focus on studying the effect of the natural compounds that are effective antimicrobials in vitro and nontoxic to adult honey bees on the honey bee larvae. Moreover, further studies on the distribution and effects of these natural products on beehive, adult honey bees, larvae, honey, RJ, and other beehive products are still necessary in order to understand pharmacokinetics and pharmacodynamics inside the beehive. As well, research on the effectiveness of these natural antimicrobials at field conditions is imperative. Moreover, further studies should be carried out on the sporicidal properties of these natural substances to destroy P. larvae spores for the prevention of AFB disease. And last but not least, the development of proper delivery modes of the natural products inside the beehives for the in vivo treatment and prevention of the illness is another important issue that requires further research, in order to put these natural strategies in practice under real beehive conditions.

\section{ACKNOWLEDGEMENTS}

This research was funded by PICT 2014 no. 3264 and Project CIC no. 1194/14. The authors would like to thank Comisión de Investigaciones Científicas (CIC), Consejo Nacional de Investigaciones Científicas y Técnicas (CONICET), and Universidad Nacional de Mar del Plata (UNMdP) for financial support. María Celeste Pellegrini thanks CIC, and Noelia Melina Cugnata, Elisa Guaspari and Fiorella Giselle De Piano thank CONICET, for their $\mathrm{Ph} . \mathrm{D}$. grants.

Authors' Contributions Rosa Maria Alonso-Salces, Noelia Melina Cugnata, Elisa Guaspari, Maria Celeste Pellegrini, Inés Aubone, Fiorella Giselle De Piano, Karina Antunez, and Sandra Rosa Fuselli contributed equally to this work.
Stratégies naturelles pour lutter contre Paenibacillus larvae, l'agent responsable de la loque américaine chez les abeilles : une synthèse

Apis mellifera / agent pathogène / loque américaine / produit de lutte naturel

Natürliche Strategien zur Kontrolle von Paenibacillus larvae, dem Erreger der Amerikanischen Faulbrut bei Honigbienen. Ein Review.

Paenibacillus larvae / Amerikanische Faulbrut / Apis mellifera / Naturprodukte

\section{REFERENCES}

Adorjan, B., Buchbauer, G. (2010) Biological properties of essential oils: an updated review. Flavour Fragr. J. 25 (6), 407-426

Albo, G. N., Cerimele, E., Re, M. S., De Giusti, M., Alippi, A. M. (2001) Ensayos de campo para evaluar la actividad de algunos aceites esenciales. Vida apíc. 108, 41-46

Albo, G. N., Henning, C., Ringuelet, J., Reynaldi, F. J., De Giusti, M. R., Alippi, A. M. (2003) Evaluation of some essential oils for the control and prevention of American foulbrood disease in honey bees. Apidologie 34 (5), 417-427

Albo, G. N., Reynaldi, F. J., Yordaz, M., Henning, C. (2008) Toxicidad de aceites esenciales con efecto fungistático sobre Ascosphaera apis en larvas y adultos de Apis mellifera. Veterinaria Cuyana 1, 16-22

Alippi, A. M. (1996) Antimicrobial activity of some essential oils against Paenibacillus larvae, causal agent of AFB. J. Herbs, Spices and Medicinal Plants 4 (2), 9-15

Alippi, A. M., Ringuelet, J., Henning, C., Bandoni, A. (2001) Actividad antimicrobiana in vitro de algunos aceites esenciales y mezclas de esencias sobre Paenibacillus larvae subsp. larvae. Vida Apíc. 106, 41-44

Alippi, A. M., Reynaldi, F. J. (2006) Inhibition of the growth of Paenibacillus larvae, the causal agent of American foulbrood of honeybees, by selected strains of aerobic spore-forming bacteria isolated from apiarian sources. J. Invertebr. Pathol. 91 (3), 141-146

Anjum, S. I., Ayaz, S., Shah, A. H., Khan, S., Khan, S. N. (2015) Controlling honeybee pathogen by using neem and Barbaka plant extracts. Biotechnol. Biotechnol. Equip. 29 (5), 901-906

Ansari, M. J., Al-Ghamdi, A., Usmani, S., Al-Waili, N., Nuru, A., Sharma, D., Khan, K. A., Kaur, M., Omer, M. (2015) In vitro evaluation of the effects of some plant essential oils on Paenibacillus larvae, the causative agent of American foulbrood. Biotechnol. Biotechnol. Equip. 30 (1), 49-55

Antúnez, K., Harriet, J., Gende, L. B., Maggi, M. D., Eguaras, M. J., Zunino, P. (2008) Efficacy of natural 
propolis extract in the control of American foulbrood. Vet. Microbiol. 131 (3-4), 324-331

Ashiralieva, A., Genersch, E. (2006) Reclassification, genotypes and virulence of Paenibacillus larvae, the etiological agent of American foulbrood in honeybees - a review. Apidologie 37 (4), 411-420

Audisio, C. M., Torres, M. J., Sabaté, D. C., Ibarguren, C., Apella, M. C. (2011) Properties of different lactic acid bacteria isolated from Apis mellifera L. bee-gut. Microbiol. Res. 166 (1), 1-13

Bachanová, K., Klaudiny, J., Kopernický, J., Šimúth, J. (2002) Identification of honeybee peptide active against Paenibacillus larvae larvae through bacterial growth-inhibition assay on polyacrylamide gel. Apidologie 33 (3), 259-269

Bamrick, J. F. (1967) Resistance to American foulbrood in honey bees: VI. Spore germination in larvae of different ages. J. Invertebr. Pathol. 9 (1), 30-34

Bastos, E. M. A. F., Simone, M., Jorge, D. M., Soares, A. E. E., Spivak, M. (2008) In vitro study of the antimicrobial activity of Brazilian propolis against Paenibacillus larvae. J. Invertebr. Pathol. 97 (3), 273-281

Benitez, L. B., Velho, R. V., De Souza Da Motta, A., Segalin, J., Brandelli, A. (2012) Antimicrobial factor from Bacillus amyloliquefaciens inhibits Paenibacillus larvae, the causative agent of American foulbrood. Arch. Microbiol. 194 (3), 177-185

Bíliková, K., Wu, G., Šimúth, J. (2001) Isolation of a peptide fraction from honeybee royal jelly as a potential antifoulbrood factor. Apidologie 32 (3), 275-283

Bíliková, K., Mirgorodskaya, E., Bukovská, G., Gobom, J., Lehrach, H., Šimúth, J. (2009) Towards functional proteomics of minority component of honeybee royal jelly: the effect of post-translational modifications on the antimicrobial activity of apalbumin2. Proteomics 9 (8), 2131-2138

Bíliková, K., Popova, M., Trusheva, B., Bankova, V. (2013) New anti-Paenibacillus larvae substances purified from propolis. Apidologie 44 (3), 278-285

Bogdanov, S. (2011) Royal jelly, bee brood: composition, health, medicine: a review. Lipids 3 (8), 8-19

Boligon, A. A., Brum, T. F. D., Zadra, M., Piana, M., Alves, C. F. D. S., Fausto, V. P., Júnior, V. D. S. B., Vaucher, R. D. A., Santos, R. C. V., Athayde, M. L. (2013) Antimicrobial activity of Scutia buxifolia against the honeybee pathogen Paenibacillus larvae. J. Invertebr. Pathol. 112 (2), 105-107

Boonsai, P., Phuwapraisirisan, P., Chanchao, C. (2014) Antibacterial activity of a cardanol from Thai Apis mellifera propolis. Int. J. Med. Sci. 11 (4), 327-336

Burdock, G. A. (1998) Review of the biological properties and toxicity of bee propolis (propolis). Food Chem. Toxicol. 36 (4), 347-363

Cecotti, R., Carpana, E., Falchero, L., Paoletti, R., Tava, A. (2012) Determination of the volatile fraction of Polygonum bistorta $\mathrm{L}$. at different growing stages and evaluation of its antimicrobial activity against two major honeybee (Apis mellifera) pathogens. Chem. Biodivers. 9 (2), 359-369
Cornman, R. S., Lopez, D., Evans, J. D. (2013) Transcriptional response of honey bee larvae infected with the bacterial pathogen Paenibacillus larvae. PLoS ONE 8 (6), e65424

Cherif, A., Rezgui, W., Raddadi, N., Daffonchio, D., Boudabous, A. (2008) Characterization and partial purification of entomocin 110, a newly identified bacteriocin from Bacillus thuringiensis subsp. entomocidus HD110. Microbiol. Res. 163 (6), 684-692

da Silva, J. F. M., de Souza, M. C., Matta, S. R., de Andrade, M. R., Vidal, F. V. N. (2006) Correlation analysis between phenolic levels of Brazilian propolis extracts and their antimicrobial and antioxidant activities. Food Chem. 99 (3), 431-435

Damiani, N., Fernández, N. J., Porrini, M. P., Gende, L. B., Álvarez, E., Buffa, F., Brasesco, C., Maggi, M. D., Marcangeli, J., Eguaras, M. J. (2014) Laurel leaf extracts for honeybee pest and disease management: antimicrobial, microsporicidal, and acaricidal activity. Parasitol. Res. 113 (2), 701-709

de Almeida Vaucher, R., Giongo, J. L., Bolzan, L. P., Côrrea, M. S., Fausto, V. P. et al. (2015) Antimicrobial activity of nanostructured Amazonian oils against Paenibacillus species and their toxicity on larvae and adult worker bees. J. Asia-Pacif. Entomol. 18 (2), 205-210

De Graaf, D. C., Alippi, A. M., Brown, M., Evans, J. D., Feldlaufer, M. et al. (2006) Diagnosis of American foulbrood in honey bees: a synthesis and proposed analytical protocols. Lett. Appl. Microbiol. 43 (6), 583-590

De Vuyst, L., Vandamme, E. J. (1994) Bacteriocins of lactic acid bacteria: microbiology, genetics and applications. London, UK: Blackie Academic \& Professional

Djukic, M., Brzuszkiewicz, E., Fünfhaus, A., Voss, J., Gollnow, K., Poppinga, L., Liesegang, H., GarciaGonzalez, E., Genersch, E., Daniel, R. (2014) How to kill the honey bee larva: genomic potential and virulence mechanisms of Paenibacillus larvae. PLoS ONE 9 (3), e90914

Eguaras, M. J., Fuselli, S. R., Gende, L. B., Fritz, R., Ruffinengo, S. R., Clemente, G., Gonzalez, A., Bailac, P. N., Ponzi, M. I. (2005) An in vitro evaluation of Tagetes minuta essential oil for the control of the honeybee pathogens Paenibacillus larvae and Ascosphaera apis, and the parasitic mite Varroa destructor. J. Essent. Oil Res. 17 (3), 336-340

Engel, P., Martinson, V. G., Moran, N. A. (2012) Functional diversity within the simple gut microbiota of the honey bee. Proc. Natl. Acad. Sci. 109 (27), 11002-11007

Evans, J. D., Armstrong, T. N. (2005) Inhibition of the American foulbrood bacterium, Paenibacillus larvae larvae, by bacteria isolated from honey bees. J. Apic. Res. 44 (4), 168-171

Evans, J. D., Armstrong, T. N. (2006) Antagonistic interactions between honey bee bacterial symbionts and implications for disease. BMC Ecol. 6 (4)

FAO/WHO. (2006) Probiotics in food: health and nutritional properties of probiotics in food including powder milk with live lactic acid bacteria, FAO food and nutrition paper 85 . World Health Organization/Food 
and Agriculture Organization of the United Nations, Rome, pp. 56

Feldlaufer, M., Lusby, W. R., Knox, D., Shimanuki, H. (1993a) Isolation and identification of linoleic acid as an antimicrobial agent from the chalkbrood fungus, Ascosphaera apis . Apidologie 24, 89-94

Feldlaufer, M. F., Knox, D. A., Lusby, W. R., Shimanuki, H. (1993b) Antimicrobial activity of fatty acids against Bacillus larvae, the causative agent of American foulbrood disease. Apidologie 24 (2), 95-99

Flesar, J., Havlik, J., Kloucek, P., Rada, V., Titera, D., Bednar, M., Stropnicky, M., Kokoska, L. (2010) In vitro growth-inhibitory effect of plant-derived extracts and compounds against Paenibacillus larvae and their acute oral toxicity to adult honey bees. Vet. Microbiol. 145 (1-2), 129-133

Floris, I., Carta, C., Moretti, M. D. L. (1996) Activity of various essential oils against Bacillus larvae white in vitro and in apiary trials. Apidologie 27 (2), 111-119

Forsgren, E., Olofsson, T. C., Vásquez, A., Fries, I. (2010) Novel lactic acid bacteria inhibiting Paenibacillus larvae in honey bee larvae. Apidologie 41 (1), 99-108

Fujiwara, S., Imai, J., Fujiwara, M., Yaeshima, T., Kawashima, T., Kobayashi, K. (1990) A potent antibacterial protein in royal jelly. Purification and determination of the primary structure of royalisin. J. Biol. Chem. 265 (19), 11333-11337

Fuselli, S. R., Gende, L. B., Garcia De La Rosa, S. B., Eguaras, M. J., Fritz, R. (2005) Inhibition of Paenibacillus larvae subsp. larvae by the essential oils of two wild plants and their emulsifying agents. Span. J. Agric. Res. 3 (2), 220-224

Fuselli, S. R., García De La Rosa, S. B., Gende, L. B., Eguaras, M. J., Fritz, R. (2006a) Inhibition of Paenibacillus larvae employing a mixture of essential oils and thymol. Rev. Argent. Microbiol. 38 (2), 89-92

Fuselli, S. R., García De La Rosa, S. B., Gende, L. B., Eguaras, M. J., Fritz, R. (2006b) Antimicrobial activity of some Argentinian wild plant essential oils against Paenibacillus larvae larvae, causal agent of American foulbrood (AFB). J. Apic. Res. 45 (1), 2-7

Fuselli, S. R., García De La Rosa, S. B., Eguaras, M. J., Fritz, R., Ndagijimana, M., Vannini, L., Guerzoni, M. E. (2007) Efficacy of indigenous plant essential oil Andean thyme (Acantholippia seriphioides a. Gray) to control American foulbrood (AFB) in honey bee (Apis mellifera L.) hives. J. Essent. Oil Res. 19 (6), 514-519

Fuselli, S. R., García De La Rosa, S. B., Eguaras, M. J., Fritz, R. (2008a) Susceptibility of the honeybee bacterial pathogen Paenibacillus larvae to essential oils distilled from exotic and indigenous Argentinean plants. J. Essent. Oil Res. 20 (5), 464-470

Fuselli, S. R., García De La Rosa, S. B., Eguaras, M. J., Fritz, R. (2008b) Chemical composition and antimicrobial activity of citrus essences on honeybee bacterial pathogen Paenibacillus larvae, the causal agent of American foulbrood. World J. Microbiol. Biotechnol. 24 (10), 2067-2072
Fuselli, S. R., Maggi, M. D., García De La Rosa, S. B., Principal, J., Eguaras, M. J., Fritz, R. (2009) In vitro antibacterial and antiparasitic effect of citrus fruit essential oils on the honey bee pathogen Paenibacillus larvae and the parasitic mite Varroa destructor. J. Apic. Res. 48 (1), 77-78

Fuselli, S. R., García de la Rosa, S. B., Eguaras, M. J., Fritz, R. (2010) In vitro antibacterial effect of exotic plants essential oils on the honeybee pathogen Paenibacillus larvae, causal agent of American foulbrood. Span. J. Agric. Res. 8 (3), 651-657

Gallardo, G. L., Peña, N. I., Chacana, P., Terzolo, H. R., Cabrera, G. M. (2004) L-tenuazonic acid, a new inhibitor of Paenibacillus larvae. World J. Microbiol. Biotechnol. 20 (6), 609-612

Gende, L. B., Floris, I., Fritz, R., Eguaras, M. J. (2008a) Antimicrobial activity of cinnamon (Cinnamomum zeylanicum ) essential oil and its main components against Paenibacillus larvae from Argentine. Bull. Insectol. 61 (1), 1-4

Gende, L. B., Principal, J., Maggi, M. D., Palacios, S. M., Fritz, R., Eguaras, M. J. (2008b) Melia azedarach extract and essential oils of Cinnamomun zeylanycum, Mentha piperita and Lavandula officinalis as a control of Paenibacillus larvae. Zootec. Trop. 26 (2), 151-156

Gende, L. B., Maggi, M. D., Damiani, N., Fritz, R., Eguaras, M. J., Floris, I. (2009a) Advances in the apiary control of the honeybee American foulbrood with cinnamon (Cinnamomum zeylanicum) essential oil. Bull. Insectol. 62 (1), 93-97

Gende, L. B., Maggi, M. D., Fritz, R., Eguaras, M. J., Bailac, P. N., Ponzi, M. I. (2009b) Antimicrobial activity of Pimpinella anisum and Foeniculum vulgare essential oils against Paenibacillus larvae. J. Essent. Oil Res. 21 (1), 91-93

Gende, L. B., Fernández, N., Buffa, F., Ruiu, L., Satta, A., Fritz, R., Eguaras, M. J., Floris, I. (2010a) Susceptibility of Paenibacillus larvae isolates to a tetracycline hydrochloride and cinnamon (Cinnamomum zeylanicum) essential oil mixture. Bull. Insectol. 63 (2), 247-250

Gende, L. B., Maggi, M. D., van Baren, C., di Leo, L., Bandoni, A., Fritz, R., Eguaras, M. J. (2010b) Antimicrobial and miticide activities of Eucalyptus globulus essential oils obtained from different Argentine regions. Span. J. Agric. Res. 8 (3), 642-650

Gende, L. B., Mendiara, S., Fernández, N. J., Van Baren, C., Di Lio Lira, A., Bandoni, A., Fritz, R., Floris, I., Eguaras, M. J. (2014) Essentials oils of some Mentha spp. and their relation with antimicrobial activity against Paenibacillus larvae, the causative agent of American foulbrood in honey bees, by using the bioautography technique. Bull. Insectol. 67 (1), 13-20

Genersch, E., Ashiralieva, A., Fries, I. (2005) Strain- and genotype-specific differences in virulence of Paenibacillus larvae subsp. larvae, a bacterial pathogen causing American foulbrood disease in honeybees. Appl. Environ. Microbiol. 71 (11), 7551-7555

Genersch, E., Forsgren, E., Pentikäinen, J., Ashiralieva, A., Rauch, S., Kilwinski, J., Fries, I. (2006) Reclassification of Paenibacillus larvae subsp. pulvifaciens and 
Paenibacillus larvae subsp. larvae as Paenibacillus larvae without subspecies differentiation. Int. J. Syst. Evol. Microbiol. 56 (3), 501-511

Genersch, E. (2010) American foulbrood in honeybees and its causative agent, Paenibacillus larvae. J. Invertebr. Pathol. 103, 10-19

González, M. J., Marioli, J. M. (2010) Antibacterial activity of water extracts and essential oils of various aromatic plants against Paenibacillus larvae, the causative agent of American foulbrood. J. Invertebr. Pathol. 104 (3), 209-213

González, M. J., Beoletto, V. G., Agnese, A. M., Audisio, M. C., Marioli, J. M. (2015) Purification of substances from Achyrocline satureioides with inhibitory activity against Paenibacillus larvae, the causal agent of American foulbrood in honeybees' larvae. Appl. Biochem. Biotechnol. 175 (7), 3349-3359

Hansen, H., Brodsgaard, C. J. (1999) American foulbrood: a review of its biology, diagnosis and control. Bee World 80 (1), 5-23

Hashemipour, M. A., Tavakolineghad, Z., Arabzadeh, S. A. M., Iranmanesh, Z., Nassab, S. A. H. G. (2014) Antiviral activities of honey, royal jelly, and acyclovir against HSV-1. Wounds 26 (2), 47-54

Hernández-López, J., Crockett, S., Kunert, O., Hammer, E., Schuehly, W., Bauer, R., Crailsheim, K., RiessbergerGallé, U. (2014) In vitro growth inhibition by Hypericum extracts and isolated pure compounds of Paenibacillus larvae, a lethal disease affecting honeybees worldwide. Chem. Biodivers. 11 (5), 695-708

Hornitzky, M. A. Z. (1998) The pathogenicity of Paenibacillus larvae subsp. larvae spores and vegetative cells to honey bee (Apis mellifera) colonies and their susceptibility to royal jelly. J. Apic. Res. 37 (4), 267-271

Hornitzky, M. A. Z. (2003) Fatty acids - an alternative control strategy for honeybee diseases: a report for the Rural Industries Research and Development Corporation, by Michael Hornitzky. Rural Industries Research and Development Corporation. Barton, A.C.T.

Jalali, A. S., Najafi, G., Hosseinchi, M., Sedighnia, A. (2015) Royal jelly alleviates sperm toxicity and improves in vitro fertilization outcome in stanozololtreated mice. Iran. J. Reprod. Med. 13 (1), 15-22

Jaouani, I., Abbassi, M. S., Alessandria, V., Bouraoui, J., Ben Salem, R., Kilani, H., Mansouri, R., Messadi, L., Cocolin, L. (2014) High inhibition of Paenibacillus larvae and Listeria monocytogenes by Enterococcus isolated from different sources in Tunisia and identification of their bacteriocin genes. Lett. Appl. Microbiol. 59 (1), 17-25

Kamel, A., Moustafa, A., Nafea, E. (2013) Propolis as a natural antibiotic to control American foulbrood disease in honey bee colonies. Afr. J. Agric. Res. 8 (23), 3047-3062

Kimura, Y. (2008) Antitumor and antimetastatic actions of various natural products. Stud. Nat. Prod. Chem. 34, 35-76

Kochansky, J., Knox, D. A., Feldlaufer, M., Pettis, J. S. (2001) Screening alternative antibiotics against oxytetracycline-susceptible and -resistant Paenibacillus larvae. Apidologie 32 (3), 215-222

Kohno, K., Okamoto, I., Sano, O., Arai, N., Iwaki, K., Ikeda, M., Kurimoto, M. (2004) Royal jelly inhibits the production of proinflammatory cytokines by activated macrophages. Biosci., Biotechnol. Biochem. 68 (1), 138-145

Kujumgiev, A., Tsvetkova, I., Serkedjieva, Y., Bankova, V. S., Christov, R., Popov, S. (1999) Antibacterial, antifungal and antiviral activity of propolis of different geographic origin. J. Ethnopharmacol. 64, 235-240

Kuzyšinová, K., Mudroňová, D., Toporčák, J., Nemcová, R., Molnár, L., Mad'ari, A., Vaníková, S., Kožár, M. (2014) Testing of inhibition activity of essential oils against Paenibacillus larvae - the causative agent of American foulbrood. Acta Vet. Brno 83 (1), 9-12

Lewis, K., Ausubel, F. M. (2006) Prospects for plant-derived antibacterials. Nat. Biotechnol. 24 (12), 1504-1507

Lindenfelser, L. A. (1968) In vivo activity of propolis against Bacillus larvae. J. Invertebr. Pathol. 12 (1), 129-131

Lokvam, J., Braddock, J. F. (1999) Anti-bacterial function in the sexually dimorphic pollinator rewards of Clusia grandiflora (Clusiaceae). Oecologia 119 (4), 534-540

Lokvam, J., Braddock, J. F., Reichardt, P. B., Clausen, T. P. (2000) Two polyisoprenylated benzophenones from the trunk latex of Clusia grandiflora (Clusiaceae). Phytochemistry 55 (1), 29-34

Lopes, L. Q., Santos, C. G., de Almeida Vaucher, R., Gende, L., Raffin, R. P., Santos, R. C. (2016) Evaluation of antimicrobial activity of glycerol monolaurate nanocapsules against American foulbrood disease agent and toxicity on bees. Microb. Pathog. 20, 183-188

Maggi, M. D., Gende, L. B., Russo, K., Fritz, R., Eguaras, M. J. (2011) Bioactivity of Rosmarinus officinalis essential oils against Apis mellifera, Varroa destructor and Paenibacillus larvae related to the drying treatment of the plant material. Nat. Prod. Res. 25 (4), 397406

Manolova, N. M., Maximova, V. A., Gegova, G. A., Serkedjieva, Y. P., Uzunov, S. T., Marekov, N. Y., Bankova, V. S. (1985) On the anti-influenza action on fractions from propolis. Dokladi na Bolgarskata Akademiya na Naukite 38 (6), 735-738

Mihai, C. M., Mârghitaș, L. A., Dezmirean, D. S., Chirilâ, F., Moritz, R. F. A., Schlüns, H. (2012) Interactions among flavonoids of propolis affect antibacterial activity against the honeybee pathogen Paenibacillus larvae. J. Invertebr. Pathol. 110 (1), 68-72

Mlagan, V., Sulimanovic, D. (1982) Action of propolis solutions on Bacillus larvae. Apiacta 17, 16-20

Moran, N. A., Hansen, A. K., Powell, J. E., Sabree, Z. L. (2012) Distinctive gut microbiota of honey bees assessed using deep sampling from individual worker bees. PLoS ONE 7 (4), e36393

Mutinelli, F. (2003) European legislation governing the authorization of veterinary medicinal products with particular reference to the use of drugs for the control of honey bee diseases. Apiacta 38, 156-168 
Nascimento, A. P., Moraes, L. A. R., Ferreira, N. U., De Padua Moreno, G., Uahib, F. G. M., Barizon, E. A., Berretta, A. A. (2015) The lyophilization process maintains the chemical and biological characteristics of royal jelly. Evidence-based Complementary and Alternative Medicine 2015, Article ID 825068, 5 pages. doi:10.1155/2015/825068

Nguyen, T. M., Kim, J. (2015a) Bacillus polymachus sp. Nov., with a broad range of antibacterial activity, isolated from forest topsoil samples by using a modified culture method. Int. J. Syst. Evol. Microbiol. 65 (2), 704-709

Nguyen, T. M., Kim, J. (2015b) Antifungal and antibacterial activities of Streptomyces polymachus sp. nov. isolated from soil. Int. J. Syst. Evol. Microbiol. 65 (8), 2385-2390

Pavel, C. I., Mărghitaș, L. A., Dezmirean, D. S., Tomoș, L. I., Bonta, V., Şapcaliu, A., Buttstedt, A. (2014) Comparison between local and commercial royal jelly - use of antioxidant activity and 10hydroxy-2-decenoic acid as quality parameter. J. Apic. Res. 53 (1), 116-123

Piana, M., De Brum, T. F., Boligon, A. A., Alves, C. F. S., De Freitas, R. B. et al. (2015) In vitro growthinhibitory effect of Brazilian plants extracts against Paenibacillus larvae and toxicity in bees. An. Acad. Bras. Cienc. 87 (2), 1041-1047

Powell, J. E., Martinson, V. G., Urban-Mead, K., Moran, N. A. (2014) Routes of acquisition of the gut microbiota of the honey bee Apis mellifera. Appl. Environ. Microbiol. 80 (23), 7378-7387

Reyes, M. G., Torres, M. J., Maggi, M. D., Marioli, J. M., Gil, R. R., Sosa, V. E., Uriburu, M. L., Audisio, M. C. (2013) In vitro inhibition of Paenibacillus larvae by different extracts and pure compounds from Flourensia spp. Ind. Crops Prod. 50, 758-763

Riley, M. A., Wertz, J. E. (2002) Bacteriocins: evolution, ecology, and application. Annu. Rev. Microbiol. 56 (1), 117-137

Roussenova, N. (2011) Antibacterial activity of essential oils against the etiological agent of American foulbrood disease (Paenibacillus larvae). Bulg. J. Vet. Med. 14 (1), 17-24

Ruffinengo, S. R., Maggi, M. D., Fuselli, S. R., Floris, I., Clemente, G., Firpo, N. H., Bailac, P. N., Ponzi, M. I. (2006) Laboratory evaluation of Heterothalamus alienus essential oil against different pests of Apis mellifera . J. Essent. Oil Res. 18 (6), 704-707
Sabaté, D. C., Carrillo, L., Carina Audisio, M. (2009) Inhibition of Paenibacillus larvae and Ascosphaera apis by Bacillus subtilis isolated from honeybee gut and honey samples. Res. Microbiol. 160 (3), 193-199

Sabaté, D. C., Gonzaléz, M. J., Porrini, M. P., Eguaras, M. J., Audisio, M. C., Marioli, J. M. (2012) Synergistic effect of surfactin from Bacillus subtilis $\mathrm{C} 4$ and Achyrocline satureioides extracts on the viability of Paenibacillus larvae. World J. Microbiol. Biotechnol. 28 (4), 1415-1422

Santos, R. C. V., Alves, C. F. D. S., Schneider, T., Lopes, L. Q. S., Aurich, C., Giongo, J. L., Brandelli, A., de Almeida Vaucher, R. (2012) Antimicrobial activity of Amazonian oils against Paenibacillus species. J. Invertebr. Pathol. 109 (3), 265-268

Santos, R. C. V., Lopes, L. Q. S., Alves, C. F. D. S., Fausto, V. P., Pizzutti, K. et al. (2014) Antimicrobial activity of tea tree oil nanoparticles against American and European foulbrood diseases agents. J. Asia-Pacif. Entomol. 17 (3), 343-347

Shimanuki, H., Knox, D. A., Feldlaufer, M. F. (1992) Honey bee disease interactions: the impact of chalkbrood on other honey bee brood diseases. Am. Bee J. 132 (11), 735-736

Sugiyama, T., Takahashi, K., Mori, H. (2012) Royal jelly acid, 10-hydroxy-trans-2-decenoic acid, as a modulator of the innate immune responses. Endocrine, Metabolic and Immune Disorders-Drug Targets 12 (4), 368-376

Vásquez, A., Forsgren, E., Fries, I., Paxton, R. J., Flaberg, E., Szekely, L., Olofsson, T. C. (2012) Symbionts as major modulators of insect health: lactic acid bacteria and honeybees. PLoS ONE 7 (3), e33188

Wilson, M. B., Brinkman, D., Spivak, M., Gardner, G., Cohen, J. D. (2015) Regional variation in composition and antimicrobial activity of US propolis against Paenibacillus larvae and Ascosphaera apis. J. Invertebr. Pathol. 124, 44-50

Yoshiyama, M., Kimura, K. (2009) Bacteria in the gut of Japanese honeybee, Apis cerana japonica, and their antagonistic effect against Paenibacillus larvae, the causal agent of American foulbrood. J. Invertebr. Pathol. 102 (2), 91-96

Yoshiyama, M., Wu, M., Sugimura, Y., Takaya, N., Kimoto-Nira, H., Suzuki, C. (2013) Inhibition of Paenibacillus larvae by lactic acid bacteria isolated from fermented materials. J. Invertebr. Pathol. 112 (1), $62-67$ 